\title{
Debating tRNA Origins
}

\author{
Michelle M. Meyer ${ }^{1}$ (D)
}

Received: 13 January 2020 / Accepted: 17 January 2020 / Published online: 29 January 2020

(c) Springer Science+Business Media, LLC, part of Springer Nature 2020

\begin{abstract}
The tRNA is a critical component in all modern translation systems as well as an important intermediate in models of early protein coding systems. In the following works, proponents for each of the major hypotheses for tRNA origin and evolution engage in discussion of the merits for each model.
\end{abstract}

Keywords tRNA $\cdot$ Origin $\cdot$ Mini-helix model $\cdot$ Ring model

The tRNA is a critical component in all modern translation systems. It is also of exceptional interest to evolutionary biologists, as it potentially occupies a key role as an intermediate in models of early protein coding systems that allow development of the modern genetic code. Yet, due to the high level of sequence and structural conservation for tRNAs across all living things, the intermediate steps toward the evolution of the quintessential tRNA structure remain largely based on models that invoke various conserved portions of the tRNA sequence or structure, and arguments of parsimony. Indeed, the elegant symmetry of the tRNA cloverleaf structure invites numerous hypotheses and thought experiments in explanation of its origins.

Proposed hypotheses described to date include a sequence accretion model (Sun and Caetano-Anollés 2007), a 2 minihelix model, a 3 mini-helix model, and a ring model. The 2 mini-helix model originally proposed by Massimilio DiGiulio in 1992 argues that tRNAs arose from a duplication and joining event (Di Giulio 1992), and he has expounded upon this essential idea in many ways since the initial proposal (Di Giulio 2012). More recently, Zachary Barton's 3 mini-helix model contends based on conserved sequences that tRNA arose from the joining of three individual minihelices (Root-Bernstein et al. 2016), and (Demongeot and
Seligmann 2019) have proposed RNA ring structures as the progenitors for tRNA.

The following three commentary pieces allow the proponents for each of these models to lay out their arguments, thus enabling The Journal of Molecular Evolution to serve as a forum for scientific discussion of this important, and still somewhat controversial, topic in evolutionary biology.

\section{References}

Demongeot J, Seligmann H (2019) More pieces of ancient than recent theoretical minimal proto-tRNA-like RNA rings in genes coding for tRNA synthetases. J Mol Evol 87:152-174. https://doi. org/10.1007/s00239-019-09892-6

Di Giulio M (1992) On the origin of the transfer RNA molecule. J Theor Biol 159:199-214

Di Giulio M (2012) The origin of the tRNA molecule: independent data favor a specific model of its evolution. Biochimie 94:1464-1466. https://doi.org/10.1016/j.biochi.2012.01.014

Root-Bernstein R, Kim Y, Sanjay A, Burton ZF (2016) tRNA evolution from the proto-tRNA minihelix world. Transcription 7:153-163. https://doi.org/10.1080/21541264.2016.1235527

Sun F-J, Caetano-Anollés G (2007) The origin and evolution of tRNA inferred from phylogenetic analysis of structure. J Mol Evol 66:21-35. https://doi.org/10.1007/s00239-007-9050-8
Communicated by David Liberles.

Michelle M. Meyer

m.meyer@bc.edu

1 Biology Department, Boston College, Chestnut Hill, MA, USA 